\title{
Photophysical Analysis of the Formation of Organic-Inorganic Trihalide Perovskite Films: Identification and Characterization of Crystal Nucleation and Growth
}

\author{
Miguel Anaya, ${ }^{\dagger}$ Juan F. Galisteo-López, ${ }^{*}{ }^{\dagger}$ Mauricio E. Calvo, ${ }^{\dagger}$ Cefe López, ${ }^{\ddagger}$ and Hernán Míguez ${ }^{*}{ }^{\dagger}$ \\ ${ }^{\dagger}$ Instituto de Ciencia de Materiales de Sevilla, Consejo Superior de Investigaciones Científicas (CSIC)-Universidad de Sevilla, \\ C/Américo Vespucio 49, 41092 Sevilla, Spain \\ ${ }^{\ddagger}$ Instituto de Ciencia de Materiales de Madrid, Consejo Superior de Investigaciones Científicas (CSIC), C/Sor Juana Inés de la Cruz \\ 3, 28049, Madrid, Spain
}

\section{Supporting Information}

ABSTRACT: In this work we demonstrate that the different processes occurring during hybrid organic-inorganic lead iodide perovskite film formation can be identified and analyzed by a combined in situ analysis of their photophysical and structural properties. Our observations indicate that this approach permits unambiguously identifying the crystal nucleation and growth regimes that lead to the final material having a cubic crystallographic phase, which stabilizes to the well-known tetragonal phase upon cooling to room temperature. Strong correlation between the dynamic and static photoemission results and the temperature-dependent X-ray diffraction data allows us to provide a description and to establish an approximate time scale for each one of the stages and their evolution. The combined characterization approach herein explored yields key information about the kinetics of the process, such as the link between the evolution of the defect density during film formation, revealed by a fluctuating photoluminescence quantum yield, and the gradual changes observed in the $\mathrm{PbI}_{2}$ related precursor structure.

\section{INTRODUCTION}

Ever since the first evidence that hybrid organic-inorganic lead-halide perovskites could outperform all other solution process approaches to fabricate photovoltaic devices, ${ }^{1-5}$ strong research efforts have been directed mainly in two directions: looking for the best solar-cell configuration (with recent reports pointing to performances rapidly approaching that of well established single crystal silicon cells ${ }^{6}$ ) and exploring more fundamental questions, essential to translating the current perovskite solar cell rush into a well-established technology. The latter includes the nature of photoexcited species, stability of the material under operating conditions, the reproducibility of efficiency measurements, the synthesis of the material, and so on. ${ }^{7,8}$ Regarding its synthesis, a number of approaches have been explored to prepare high-quality perovskite films ranging from vacuum evaporation, ${ }^{9,10}$ to solution process techniques. $^{11-13}$ Among the latter, spin coating is the most widespread approach representing the best compromise between material quality, feasibility of mass-production, and low-cost processing, leading to high-performance photovoltaic devices as well as light-emitting ones with outstanding efficiency. ${ }^{14}$

The morphology of the fabricated material (crystal size distribution and shape as well as their connectivity and final film texture), determining its operation in both photovoltaic and emitting materials is strongly determined by the growth process. In this respect, a number of articles ${ }^{12,15-24}$ have recently studied the steps that link the initial precursors to the final material during the solution process of organic-inorganic lead halide perovskite $\left(\mathrm{CH}_{3} \mathrm{NH}_{3} \mathrm{PbX}_{3}\right.$, where $\mathrm{X}$ corresponds to $\mathrm{Cl}, \mathrm{Br}$, or I) films. These studies, carried out mainly from structural information concerning electron microscopy images and X-ray diffraction (XRD) experiments, have focused on different aspects of the material formation. These include the effect of annealing conditions, ${ }^{15,20}$ and its rate, ${ }^{16}$ the evolution of the crystallization process, ${ }^{12,18,21,24}$ or the nature of the intermediate precursor species that precede perovskite formation, ${ }^{12,17,19,21,22}$ all of them leading to the fabrication of samples with better crystalline quality.

In this work we present a combined optical and structural study comprising the time evolution of the photoluminescence (PL) spectra and decay rates as well as the XRD collected in situ during the annealing in air of $\mathrm{CH}_{3} \mathrm{NH}_{3} \mathrm{PbI}_{3}$ films just after spin coating the precursors of the material. While only two stages in material formation are evident from XRD data, its combination with photophysical measurements reveals four different time intervals where nucleation of crystallites and

Received: January 13, 2016

Published: January 15, 2016 
subsequent crystal growth seem to dominate. Strong fluctuations in the PL quantum yield are evident throughout the process and correlated with the evolution of $\mathrm{PbI}_{2}$-related precursor species and sample morphology. A full time line for the perovskite formation is proposed that could help to improve the material quality by modifying the process at each of the different steps. Finally, once the annealing process has come to an end, changes in the photophysical and structural properties evidence a transition from the cubic to the tetragonal crystalline phase upon cooling of the annealed material to room temperature.

\section{EXPERIMENTAL DETAILS}

Sample Preparation. $\mathrm{CH}_{3} \mathrm{NH}_{3} \mathrm{PbI}_{3}$ films were prepared following a previously described approach ${ }^{13}$ based on a solventannealing crystallization method.

Photophysical Characterization. After the $20 \mathrm{~s}$ spin step ended samples were placed on top of a Peltier Cell set at 100 ${ }^{\circ} \mathrm{C}$ to carry out the photophysical study in an air atmosphere. A black metal plate was placed between the cell and the sample to avoid reflections of the pump beam. The sample was illuminated with a pulsed femtosecond laser source (OPerASolo from Coherent, delivering 150 fs long pulses with a repetition rate of $1 \mathrm{kHz}$ and a $\lambda=532 \mathrm{~nm}$ ) focused with an achromatic $10 \mathrm{~cm}$ focal length lens producing a spot size of 40 $\mu \mathrm{m}$, which also acted as collection optics. PL spectra were collected with a fiber-coupled spectrophotometer (USB4000 from Ocean Optics). Lifetime measurements were carried out using a time-correlated single photon counting card (SPC-130 from Becker \& Hickl).

XRD Measurements. Temperature-controlled XRD measurements were collected in a Philips X'pert PRO diffractometer with a high-temperature chamber (ANTON PAAR HTK 1200) attached. Acquisition of the samples was taken in the 5-20 $2 \theta$ range with a 0.05 step in air atmosphere.

\section{RESULTS AND DISCUSSION}

After annealing over a period of $90 \mathrm{~min}$, the samples, comprising films having large (over $1 \mu \mathrm{m}$ dimensions inplane) domains with a thickness of $300 \mathrm{~nm}$ (see Figure S1), present a strong PL peak centered at $770 \mathrm{~nm}$. Lifetime measurements were performed for an increasing pump power ranging from $10 \mathrm{nw}$ to $2 \mu \mathrm{W}$, and the appropriate pump conditions were extracted to ensure that we are in the monomolecular recombination regime (see Figure S2). Under these conditions recombination dynamics are dominated by the filling of trap states associated with the presence of defects. ${ }^{25,26}$ Studying the photophysics in this regime is relevant to take into account the role of defects during the sample formation. Next we focused on the heating process commonly used to anneal the perovskites. As a first step XRD data were collected as a function of time while the sample was heated to $100{ }^{\circ} \mathrm{C}$. Figure la,b shows data taken at two times of the heating process, 1 and $100 \mathrm{~min}$ after precursor deposition. This time interval allows the sample to achieve a region where material formation seems complete and no signs of degradation (such as the characteristic color change to yellow or changes in the XRD or PL data) were observed. In the angular range under consideration two peaks were studied: one around $2 \theta=14^{\circ}$ characteristic of the (110) planes of the tetragonal $\mathrm{CH}_{3} \mathrm{NH}_{3} \mathrm{PbI}_{3}$ phase or the (100) of the cubic phase (detailed crystallographic information on the different $\mathrm{CH}_{3} \mathrm{NH}_{3} \mathrm{PbI}_{3}$ phases has been provided by Baikie and
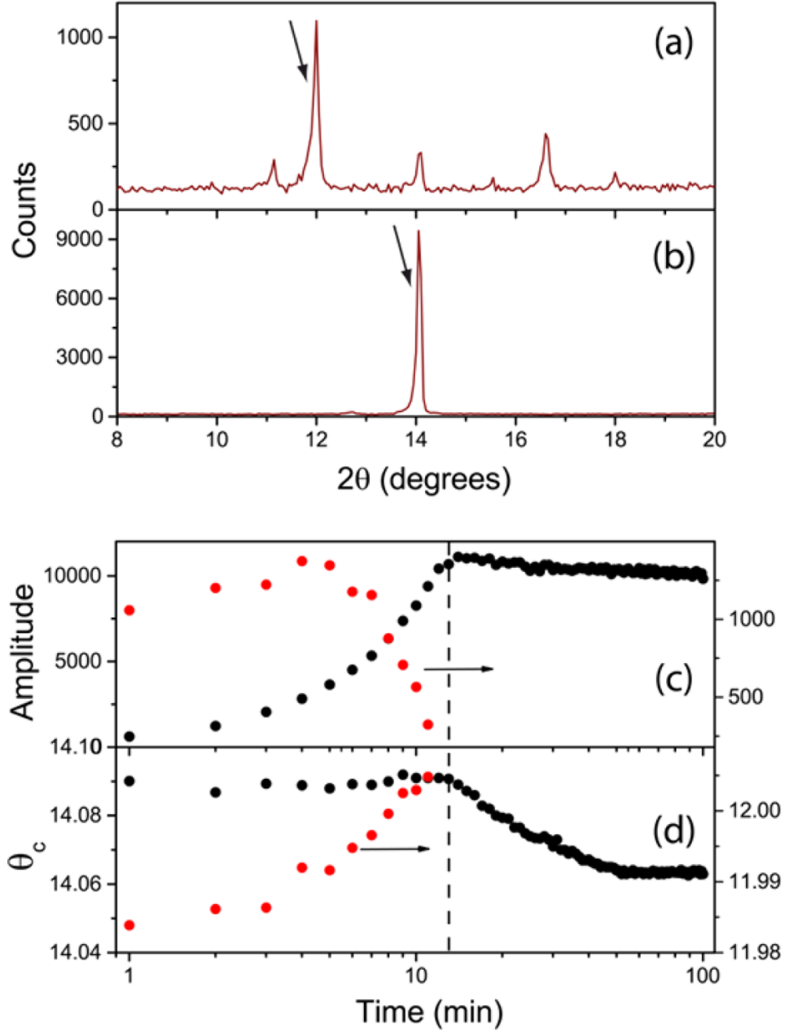

Figure 1. XRD data of thin-film perovskites collected at two points of the annealing process: 1 (a) and $100 \mathrm{~min}$ (b) after precursor deposition. Diffraction peaks associated with $\mathrm{CH}_{3} \mathrm{NH}_{3} \mathrm{PbI}_{3}$ and $\mathrm{PbI}_{2}-$ related precursors are indicated with arrows. Evolution of the intensity maximum of the XRD peak (c) corresponding to $\mathrm{CH}_{3} \mathrm{NH}_{3} \mathrm{PbI}_{3}$ (black) and precursor species (red circles) and angular position (d) as a function of anneal time.

coworkers $^{27}$ ) and another just below $2 \theta=12^{\circ}$ associated with intermediate $\mathrm{PbI}_{2}$-related precursor species, which will get consumed during perovskite formation. ${ }^{18}$ Both peaks appear highlighted by arrows in the Figure. To follow the evolution of both species during annealing we have extracted the intensity maxima of each peak as a function of time.

A trend similar to that presented by Unger and coworkers ${ }^{18}$ and Moore and coworkers ${ }^{19}$ is observed, where a monotonic increase in the $\mathrm{CH}_{3} \mathrm{NH}_{3} \mathrm{PbI}_{3}$ related peak is accompanied by a drop in the peak associated with the presence of the intermediate precursor species (see Figure 1c). Such trends indicate the formation of the perovskite species as the lead precursor disappears. Ref 19 presents an analysis of this evolution from which they extract the activation energy for the precursor-to-perovskite transition but does not allow discerning between the nucleation and crystal growth processes involved in the $\mathrm{CH}_{3} \mathrm{NH}_{3} \mathrm{PbI}_{3}$ formation. We have further extracted the angular position of the peaks corresponding to the two species, a small shift in the position being evident (Figure 1d). We shall come back to this point later on.

To gain further knowledge into the formation process we have studied the photophysics of the samples during annealing. As a first step, PL spectra were collected at different times of the process $\left(T=100{ }^{\circ} \mathrm{C}\right)$ while the sample was pumped with $500 \mathrm{nW}$. Furthermore, for the power and small duty cycle associated with these pump conditions no changes in intensity due to photoinduced processes ${ }^{28}$ were observed. Figure $2 \mathrm{a}, \mathrm{b}$ shows the spectral position and amplitude of the PL peak as a 


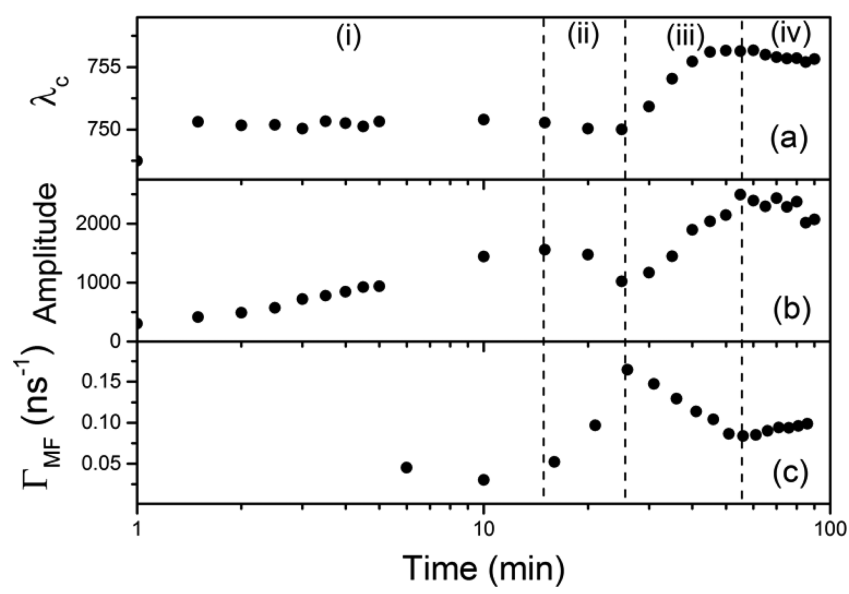

Figure 2. Time evolution during the annealing process of spectral position (a) and amplitude (b) of the PL peak and most frequent value of the decay rate distribution (c). Four regimes corresponding to four different perovskite film formation stages (see text) are separated by vertical dashed lines.

function of anneal time. Here four different regimes can be clearly observed. For a time interval (i) similar to that taken by $\mathrm{PbI}_{2}$-related precursor species to disappear (ca. $15 \mathrm{~min}$, see Figure 1c) the PL peak remains fixed in spectral position but monotonically increases its intensity. After a $10 \mathrm{~min}$ interval where the PL intensity slightly decreases while maintaining its spectral position, stage (ii), the PL further rises in amplitude and is accompanied by a red shift in the peak. This period (iii) lasts nearly $30 \mathrm{~min}$ and then a final stage is achieved (iv), which we identify with the end of the annealing process. The time needed to reach this last stage is similar to previous reports where the crystallization of the perovskite film was considered completed. $^{12,18}$

Finally, we have performed time-resolved measurements to obtain the PL decay dynamics of the material during its formation in the annealing process. Under the previously mentioned pump conditions we are in the monomolecular recombination regime (see Figure S2) where the presence of defects determines the dynamics of the PL and thus changes in the density of trap states are expected to be reflected in the PL lifetime. Measurements were carried out on different samples than those used for XRD although under identical heating conditions to compare them. The dynamics of the PL of the deposited samples were observed to strongly vary as the annealing time increased (see Figure S3). To correlate these changes with those previously described, we fitted the data to a decay rate distribution and extracted the most frequent value for each annealing time $\left(\Gamma_{\mathrm{MF}}\right)$. Figure $2 \mathrm{c}$ shows the time evolution of the decay rates, where measurements were collected over a period of $5 \mathrm{~min}$ to have enough signal. As for XRD data, PL decay measurements were repeated on different samples and similar results were obtained.

During stage (i) the monotonic increase in PL intensity (Figure $2 \mathrm{~b}$ ) coincides with the rise of the amplitude of the XRD peak corresponding to the perovskite (Figure 1c), evidencing the formation of $\mathrm{CH}_{3} \mathrm{NH}_{3} \mathrm{PbI}_{3}$ as more crystals contribute to Bragg diffraction. Also during this interval the angular position, as seen in Figure 1d (black dots), and width (not shown) of the XRD peak do not vary. This data indicates that stage (i) corresponds to the nucleation of perovskite crystallites during the annealing process.

If we consider now the PL decay dynamics (Figure 2c) we see how during stage (ii) a rapid increase in the decay rate takes place. This is accompanied by a decrease in the PL intensity. These changes point to a decrease in the quantum yield (QY) of the material, likely related to the presence of nonradiative recombination paths associated with crystalline defects. This drop in the QY coincides with the vanishing of the XRD intensity of the $\mathrm{PbI}_{2}$-related precursor (Figure 1c) which seems to be acting as a "passivating" agent of the formed crystallites. If one considers the angular position of the precursor XRD peak (red dots in Figure 1d), the drop of its intensity is accompanied by a shift to larger angles closer to the value expected for pure $\mathrm{PbI}_{2} \cdot{ }^{29}$ A plausible explanation for this behavior is illustrated in Figure 3, where a schematic description of the crystal growth process is provided along with the concomitant changes in the precursor and perovskite structures.

The perovskite crystallites form in the presence of a precursor whose nature could be $\mathrm{PbI}_{2}$ planes intercalated with DMF as well as MAI molecules, which separate the crystallographic planes of the inorganic material (Figure 3a,b). ${ }^{30}$ As nucleation proceeds, new perovskite crystallites (a)
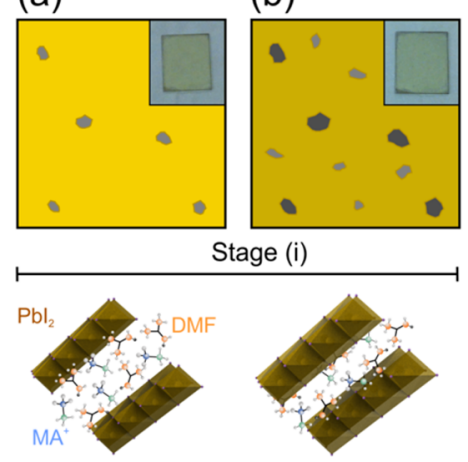

(c)

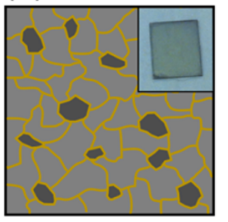

Stage (ii)
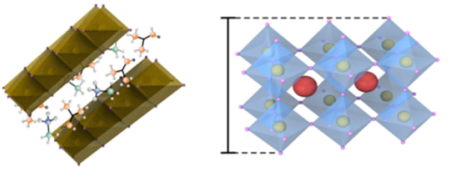

(d)

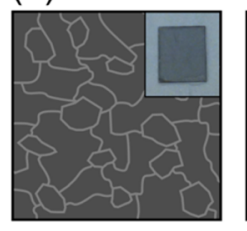

(e)
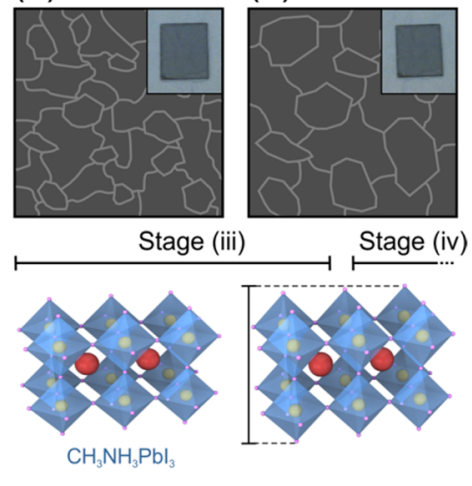

10

Time (min)

Figure 3. Schematic representation of the $\mathrm{CH}_{3} \mathrm{NH}_{3} \mathrm{PbI}_{3}$ formation during the annealing process. (a,b) Perovskite crystallites (gray regions) form in a medium comprising a $\mathrm{PbI}_{2}$-related precursor (yellow region). (c) All crystallites form at the expense of the precursor. (d,e) Crystal growth takes place as different crystallites coalesce. Insets show photographs of the samples at different stages of the annealing process: $5,10,20,40$, and 90 min. 

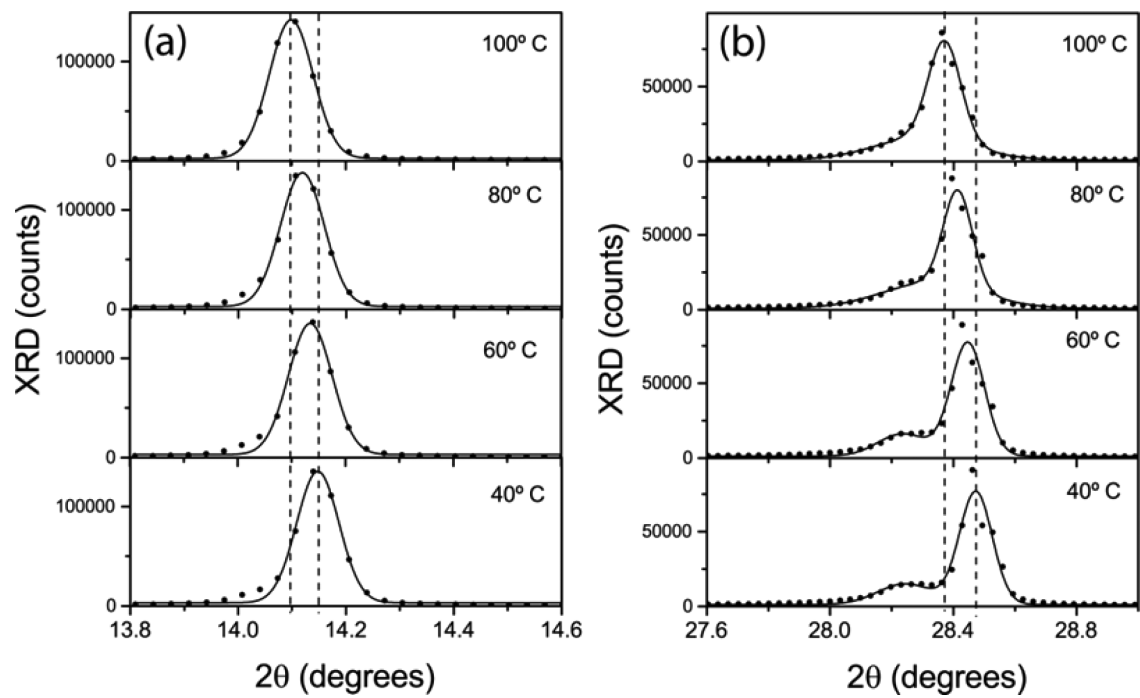

Figure 4. $\mathrm{XRD}$ data collected as a $\mathrm{CH}_{3} \mathrm{NH}_{3} \mathrm{PbI}_{3}$ film was gradually cooled from 100 (i.e., the annealing temperature) to $40{ }^{\circ} \mathrm{C}$. Graphs (a) and (b) correspond to angular ranges where characteristic diffraction peaks are expected for the cubic and tetragonal phases of the perovskite material. Full circles correspond to experimental data and lines are fits to a Gaussian line shape. Vertical lines highlight the angular position of the main diffraction peaks at the start and end temperatures.

form and the intercalated DMF molecules evaporate, causing the $\mathrm{PbI}_{2}$ planes to become closer together, this being at the origin of the narrower interplanar spacing revealed in Figure 1d (red dots). At a certain point, corresponding to the stage (ii), all crystallites are formed at the expense of the precursor. As it disappears, the newly formed grain boundaries (Figure 3c) introduce carrier traps that act as nonradiative decay paths that yield the sudden drop of photoemission efficiency observed (Figure 2b). This time interval corresponds to the early stages of the annealing process for which previous work has reported the existence of intermediate precursor species. ${ }^{12,17,19,21,22}$

As we enter the third regime (iii) the PL decay rate monotonically decreases until it reaches the constant value characteristic of region (iv). This is accompanied by a number of changes in some of the other magnitudes we have monitored. As the amplitude of the XRD peak associated with the crystalline $\mathrm{CH}_{3} \mathrm{NH}_{3} \mathrm{PbI}_{3}$ remains constant we assume that the total amount of perovskite does not change. At this point, crystal growth of large domains at the expense of smaller crystallites is probably taking over (Figure 3d,e). This is in agreement with the fact that the PL intensity further increases (see Figure $2 b$ ), as larger crystallites present a smaller density of surface defects that are expected to reduce the $\mathrm{QY}$ of the material. The hypothesis of crystal growth is further supported by a red shift of the PL peak (Figure 2a) and a decrease in the decay dynamics. This behavior has been previously observed by D'Innocenzo and coworkers ${ }^{31}$ as a signature of increasing perovskite crystal size. In that work, the origin of this behavior was attributed to the release of strain present in the crystalline lattice as a consequence of the distortion of the $\mathrm{Pb}-\mathrm{I}-\mathrm{Pb}$ bond. This is in agreement with the monotonic enlargement of the interplanar spacing revealed by the change in the position of the XRD peak associated with the $\mathrm{CH}_{3} \mathrm{NH}_{3} \mathrm{PbI}_{3}$ (see black dots in Figure 1d) during this third time interval. Indeed, a difference in the XRD peak position of similar magnitude has been observed when comparing $\mathrm{CH}_{3} \mathrm{NH}_{3} \mathrm{PbI}_{3}$ grown on a flat substrate and in a mesostructure, the latter constraining the space for crystal growth. ${ }^{23}$
According to this picture the annealing process necessary for the formation of $\mathrm{CH}_{3} \mathrm{NH}_{3} \mathrm{PbI}_{3}$ upon spin-coating consists of four different regimes. These comprise the nucleation of small crystallites (i), a transitional stage during which a large number of grain boundaries are formed as precursors vanish (ii), an actual crystal growth period where different crystals coalesce (iii), and a final stage (iv) where the material is eventually formed. Furthermore, this whole picture can be accessed only through the combined use of in situ XRD and photophysical measurements as certain aspects of the structural changes revealed by the former can be interpreted only through information contained in the latter.

At this point we note that the photophysics of the samples at the end of the annealing process differ from those of a sample left to cool under ambient conditions for a few hours. In particular, the PL undergoes a slight red shift of ca. $15 \mathrm{~nm}$ (see Figure S4), similar to that recently reported as $\mathrm{CH}_{3} \mathrm{NH}_{3} \mathrm{PbI}_{3}$ films were heated and ascribed to the phase change from cubic to tetragonal expected for this material at $42-57^{\circ} \mathrm{C} .{ }^{32}$ As the annealing process takes place well above such temperature, the phase of the as-prepared films is then expected to be cubic, changing to tetragonal as the sample cools. As a matter of fact, XRD collected at different temperatures below the annealing one (see Figure 4) show a shift to higher angles of the diffraction peak at $\sim 14^{\circ}$. A change of similar magnitude $\left(0.05^{\circ}\right)$ is expected to take place as one considers Bragg diffraction from the (100) planes of the cubic phase and from the (110) planes of the tetragonal phase. This point is further supported by the fact that the corresponding second-order diffraction (around $28^{\circ}$ ) shifts to larger angles and splits into two, as expected from the (200) diffraction of the cubic phase and the (004) and (220) of the tetragonal phase. ${ }^{27}$ Finally, as the sample cools from the annealing temperature, the decay rate is reduced by nearly one order of magnitude. Such change is probably due to the fact that the crystallization of the sample continues once the annealing process is interrupted, albeit at a slower pace, something that has been recently observed by Yamada and coworkers. $^{33}$ 


\section{CONCLUSIONS}

In summary, we have studied the process of hybrid organicinorganic perovskite formation during annealing by simultaneously carrying out real-time in situ structural and photophysical characterization. The combination of both types of experiments proves crucial to unveil different mechanisms taking place during the material formation. These include fluctuations in the PL QY associated with crystal morphology changing as precursors disappear or the transition from the asgrown cubic crystalline phase, generated during the annealing, to the well-known tetragonal phase achieved by cooling the sample to room temperature. While the transition from kinetically favorable nucleation to the thermodynamically stable crystal growth is a complicated process, from which retrieving information on the different steps is a difficult task, we believe the present results constitute a step further in understanding the process of formation of $\mathrm{CH}_{3} \mathrm{NH}_{3} \mathrm{PbI}_{3}$. Furthermore, we note that while applied for a specific synthetic route and material, the present study can be generalized as a tool to explore the processes leading to the formation of any hybrid organic-inorganic perovskite demanding a post-deposition (being solution process or vacuum) treatment. A precise knowledge of all of the intermediate stages could pave the way to a deeper control of the morphology of the perovskite material and hence of the performance of the final photovoltaic or light-emitting device.

\section{ASSOCIATED CONTENT}

\section{S Supporting Information}

The Supporting Information is available free of charge on the ACS Publications website at DOI: 10.1021/acs.jpcc.6b00398.

SEM image; PL dynamics as a function of pump intensity; fitting model for PL decays; PL decays at different stages of the annealing process; and PL spectra at the end of the annealing process and after cooling to room temperature. (PDF)

\section{AUTHOR INFORMATION}

\section{Corresponding Authors}

*J.G.: E-mail: juan.galisteo@csic.es.

*H.M.: E-mail: h.miguez@csic.es.

\section{Notes}

The authors declare no competing financial interest.

\section{ACKNOWLEDGMENTS}

The research leading to these results has received funding from the European Research Council under the European Union's Seventh Framework Programme (FP7/2007-2013)/ERC Grant Agreement No. 307081 (POLIGHT) and the Spanish Ministry of Economy and Competitiveness under Grants MAT201454852-R and MAT2012-31659 and Comunidad de Madrid programme S2013/MIT-2740. M.A. is grateful to La Caixa Foundation for its financial support.

\section{REFERENCES}

(1) Kojima, A.; Teshima, K.; Shirai, Y.; Miyasaka, T. Organometal Halide Perovskites as Visible-Light Sensitizers for Photovoltaic Cells. J. Am. Chem. Soc. 2009, 131, 6050-6051.

(2) Im, J. H.; Lee, C. R.; Lee, J. W.; Park, S. W.; Park, N. G. 6.5\% efficient perovskite quantum-dot-sensitized solar cell. Nanoscale 2011, 3, 4088-4093.
(3) Chung, I.; Lee, B.; He, J.; Chang, R. P. H.; Kanatzidis, M. G. Allsolid-state dye-sensitized solar cells with high efficiency. Nature 2012, 485, 486-489.

(4) Kim, H. S.; Lee, C. R.; Im, J. H.; Lee, K. B.; Moehl, T.; Marchioro, A.; Moon, S. J.; Humphry-Baker, R.; Yum, J. H.; Moser, J. E.; Grätzel, M.; Park, N. G. Lead Iodide Perovskite Sensitized AllSolid-State Submicron Thin Film Mesoscopic Solar Cell with Efficiency Exceeding 9\%. Sci. Rep. 2012, 2, 591.

(5) Lee, M. M.; Teuscher, J.; Miyasaka, T.; Murakami, T. N.; Snaith, H. J. Efficient Hybrid Solar Cells Based on Meso-Superstructured Organometal Halide Perovskites. Science 2012, 338, 643-647.

(6) See NREL's Efficiency Chart (http://www.nrel.gov/ncpv/ images/efficiency chart.jpg) for the latest certified efficiency update.

(7) Christians, J. A.; Manser, J. S.; Kamat, P. V. The Multifaceted Excited State of $\mathrm{CH}_{3} \mathrm{NH}_{3} \mathrm{PbI}_{3}$. Charge Separation, Recombination, and Trapping. J. Phys. Chem. Lett. 2015, 6, 2086-2095.

(8) Egger, D. A.; Edri, E.; Cahen, D.; Hodes, G. Perovskite Solar Cells: Do We Know What We Do Not Know? J. Phys. Chem. Lett. 2015, 6, 279-282.

(9) Liu, M.; Johnston, M. B.; Snaith, H. J. Efficient Planar Heterojunction Perovskite Solar Cells by Vapour Deposition. Nature 2013, 501, 395-398.

(10) Chen, C.-W.; Kang, H.-W.; Hsiao, S.-Y.; Yang, P.-F.; Chiang, K.M.; Lin, H.-W. Efficient and Uniform Planar-Type Perovskite Solar Cells by Simple Sequential Vacuum Deposition. Adv. Mater. 2014, 26, 6647-6652.

(11) Burschka, J.; Pellet, N.; Moon, S.-J.; Humphry-Baker, R.; Gao, P.; Nazeeruddin, M. K.; Grätzel, M. Sequential Deposition as a Route to High-Performance Perovskite-Sensitized Solar Cells. Nature 2013, 499, 316-319.

(12) Jeon, N. J.; Noh, J. H.; Kim, Y. C.; Yang, W. S.; Ryu, S.; Seok, S. I. Solvent Engineering for High-Performance Inorganic-Organic Hybrid Perovskite Solar Cells. Nat. Mater. 2014, 13, 897-903.

(13) Xiao, M.; Huang, F.; Huang, W.; Dkhissi, Y.; Zhu, Y.; Etheridge, J.; Gray-Weale, A.; Bach, U.; Cheng, Y.-B.; Spiccia, L. A Fast Deposition-Crystallization Procedure for Highly Efficient Lead Iodide Perovskite Thin-Film Solar Cells. Angew. Chem., Int. Ed. 2014, 53, 9898-9903.

(14) Cho, H.; Jeong, S.-H.; park, M.-H.; Kim, Y.-H.; Wolf, C.; Lee, C.-L.; Heo, J. H.; Sadhanala, A.; Myoung, N.; Yoo, S.; Im, S. H.; Friend, R. H.; Lee, T.-W. Overcoming the Electroluminescence Efficiency Limitations of Perovskite Light-Emitting Diodes. Science 2015, 350, 1222-1225.

(15) Dualeh, A.; Tétreault, N.; Moehl, T.; Gao, P.; Nazeeruddin, M. K.; Grätzel, M. Effect of Annealing Temperature on Film Morphology of Organic-Inorganic Hybrid Pervoskite Solid-State Solar Cells. Adv. Funct. Mater. 2014, 24, 3250-3258.

(16) Saliba, M.; Tan, K. W.; Sai, H.; Moore, D. T.; Scott, T.; Zhang, W.; Estroff, L. A.; Wiesner, U.; Snaith, H. J. Influence of Thermal Processing Protocol upon the Crystallization and Photovoltaic Performance of Organic-Inorganic Lead Trihalide Perovskites. J. Phys. Chem. C 2014, 118, 17171-17177.

(17) Tan, K. W.; Moore, D. T.; Saliba, M.; Sai, H.; Estroff, L. A.; Hanrath, T.; Snaith, H. J.; Wiesner, U. Thermally Induced Structural Evolution and Performance of Mesoporous Block CopolymerDirected Alumina Perovskite Solar Cells. ACS Nano 2014, 8, 47304739.

(18) Unger, L. E.; Bowring, A. R.; Tassone, C. J.; Pool, V. L.; GoldParker, A.; Cheacharoen, R.; Stone, K. H.; Hoke, E. T.; Toney, M. F.; McGehee, M. D. Chloride in Lead Chloride-Derived Organo-Metal Halides for Perovskite-Absorber Solar Cells. Chem. Mater. 2014, 26, $7158-7165$.

(19) Moore, D. T.; M; Sai, H.; Tan, K. W.; Smilgies, D.-M.; Zhang, W.; Snaith, H. J.; Wiesner, U.; Estroff, L. A. Crystallization Kinetics of Organic-Inorganic Trihalide Perovskites and the Role of the Lead Anion in Crystal Growth. J. Am. Chem. Soc. 2015, 137, 2350-2358.

(20) Xiao, Z.; Dong, Q.; Bi, C.; Shao, Y.; Yuan, Y.; Huang, J. Solvent Annealing of Perovskite-Induced Crystal Growth for PhotovoltaicDevice Efficiency Enhancement. Adv. Mater. 2014, 26, 6503-6509. 
(21) Zhang, W.; Saliba, M.; Moore, D. T.; Pathak, S. K.; Hörantner, M. T.; Stergiopoulos, T.; Stranks, S. D.; Eperon, G. E.; AlexanderWebber, J. A.; Abate, A.; Sadhanala, A.; Yao, S.; Chen, Y.; Friend, R. H.; Estroff, L. A.; Wiesner, U.; Snaith, H. J. Ultrasmooth organicinorganic perovskite thin-film formation and crystallization for efficient planar heterojunction solar cells. Nat. Commun. 2015, 6, 6142.

(22) Manser, J. S.; Reid, B.; Kamat, P. V. Evolution of OrganicInorganic Lead Halide Perovskite from Solid-State Iodoplumbate Complexes. J. Phys. Chem. C 2015, 119, 17065-17063.

(23) Grancini, G.; Marras, S.; Prato, M.; Giannini, C.; Quarti, C.; De Angelis, F.; De Bastiani, M. D.; Eperon, G. E.; Snaith, H. J.; Manna, L.; Petrozza, A. J. The Impact of the Crystallization Processes on the Structural and Optical Properties of Hybrid Perovskite Films for Photovoltaics. J. Phys. Chem. Lett. 2014, 5, 3836-3842.

(24) Moore, D. T.; Tan, K. W.; Sai, H.; Barteau, K. P.; Wiesner, U.; Estroff, L. A. Direct Crystallization Route to Methylammonium Lead Iodide Perovskite from an Ionic Liquid. Chem. Mater. 2015, 27, 31973199.

(25) Stranks, S. D.; Burlakov, V. M.; Leijtens, T.; Ball, J. M.; Goriely, A.; Snaith, H. J. Recombination Kinetics in Organic-Inorganic Perovskites: Excitons, Free Charge, and Subgap States. Phys. Rev. Appl. 2014, 2, 034007.

(26) Yamada, Y.; Nakamura, T.; Endo, M.; Wakamiya, A.; Kanemitsu, Y. Photocarrier Recombination Dynamics in Perovskite CH3NH3PbI3 for Solar Cell Applications. J. Am. Chem. Soc. 2014, 136, 1161011613.

(27) Baikie, T.; Fang, Y.; Kadro, J. M.; Schreyer, M.; Wei, F.; Mhaisalkar, S. G.; Graetzel, M.; White, T. J. Synthesis and Crystal Chemistry of the Hybrid Perovskite (CH3NH3)PbI3 for Solid-State Sensitised Solar Cell Applications. J. Mater. Chem. A 2013, 1, 56285641.

(28) Galisteo-López, J. F.; Anaya, M.; Calvo, M. E.; Míguez, H. Environmental effects on the photophysics of organic-inorganic halide perovskites. J. Phys. Chem. Lett. 2015, 6, 2200-2205.

(29) Zheng, Z.; Liu, A.; Wang, S.; Wang, Y.; Li, Z.; Lau, W. M.; Zhang, L. In Situ Growth of Epitaxial Lead Iodide Films Composed of Hexagonal Single Crystals. J. Mater. Chem. 2005, 15, 4555-4559.

(30) Shen, D.; Yu, X.; Cai, X.; Peng, M.; Ma, Y.; Su, X.; Xiao, L.; Zou, D. Understanding the Solvent-Assisted Crystallization Mechanism Inherent in Efficient Organic-Inorganic Halide Perovskite Solar Cells. J. Mater. Chem. A 2014, 2, 20454-20461.

(31) D’Innocenzo, V.; Kandada, A. R. S.; De Bastiani, M.; Gandini, M.; Petrozza, A. Tuning the Light Emission Properties by Band Gap Engineering in Hybrid Lead Halide Perovskite. J. Am. Chem. Soc. 2014, 136, 17730-17733.

(32) Milot, R. L.; Eperon, G. E.; Snaith, H. J.; Johnston, M. B.; Herz, L. M. Temperature-Dependent Charge-Carrier Dynamics in $\mathrm{CH}_{3} \mathrm{NH}_{3} \mathrm{PbI}_{3}$ Perovskite Thin Films. Adv. Funct. Mater. 2015, 25, 6218-6227.

(33) Yamada, Y.; Nakamura, T.; Endo, M.; Wakamiya, A.; Kanemitsu, Y. Spontaneous Defect Annihilation in $\mathrm{CH} 3 \mathrm{NH} 3 \mathrm{PbI} 3$ Thin Films at Room Temperature Revealed by Time-Resolved Photoluminescence Spectroscopy. J. Am. Chem. Soc. 2014, 136, 11610-11613. 